\title{
The Effect of Intrathecal Magnesium Sulphate on Bupivacaine-Fentanyl Subarachnoid Block for Infraumbilical Surgeries
}

\author{
Jayashree Sen ${ }^{1}$, Shreshtha Singh², Bitan Sen ${ }^{3}$ \\ ${ }^{1}$ Department of Anaesthesia, DMIMS, Sawangi, Wardha, Maharashtra, India. ${ }^{2}$ Department of \\ Anaesthesia, DMIMS, Sawangi, Wardha, Maharashtra, India. ${ }^{3}$ Department of Critical Care \\ Medicine, Bombay Hospital Institute of Medical Sciences, Mumbai, Maharashtra, India.
}

\section{ABSTRACT}

\section{BACKGROUND}

Local anaesthetics with additives in a wide range, affect the versatility of spinal anaesthesia. Amongst a diverse class of drugs, phenylpiperidine derivative fentanyl, NMDA receptor blocker magnesium have been added as adjuvants to amide local anaesthetic hyperbaric bupivacaine for spinal anaesthesia in an attempt to prolong analgesia.

\section{METHODS}

70 patients of either gender were selected randomly and were divided into two groups of 35 each. Administered intrathecally in Group S (control) $12.5 \mathrm{mg}$ of hyperbaric bupivacaine, $25 \mathrm{mcg}$ of fentanyl, $1 \mathrm{~mL}$ of normal saline and in Group M (study) $12.5 \mathrm{mg}$ of hyperbaric bupivacaine, $25 \mathrm{mcg}$ of fentanyl, $50 \mathrm{mg}$ of magnesium sulphate.

\section{RESULTS}

Insignificant haemodynamic variability was observed following the addition of magnesium to the spinal block agent. Onset (min.) of sensory block was $7.8 \pm$ 1.2 in group $\mathrm{M}, 5.3 \pm 1.0$ in group $\mathrm{S}$ which was statistically significant with pvalue of $<0.00001$. Onset (min.) of motor block was $13.2 \pm 1.5$ in group M, 10.4 \pm 2.1 in group $\mathrm{S}$ which was statistically significant (p- value $<0.00001$ ). Duration of analgesia (min) was $290.3 \pm 9.5$ in group $M$ and $261.3 \pm 12.2$ in group $\mathrm{S}$ which was statistically significant with $\mathrm{p}$ - value $<0.00001$. The recovery from the motor block (min) was $242.5 \pm 9.4$ in group $\mathrm{M}, 236.5 \pm 5.5$ in group $\mathrm{S}$, the difference was statistically significant (p-value of 0.002 ). At 8th $\mathrm{hr}$ mean of VAS was $3.65 \pm 0.90$ in Group M, $4.62 \pm 0.68$ in Group S, statistically significant, with p-value of $<0.00001$

\section{CONCLUSIONS}

Magnesium added to hyperbaric bupivacaine with fentanyl for spinal anaesthesia significantly prolongs the onset and duration of analgesia, onset and recovery from motor block, less score of VAS, without significant haemodynamic variations and adverse effects.

\section{KEY WORDS}

Analgesia, Bupivacaine, Fentanyl, Magnesium, Spinal Block

\author{
Corresponding Author: \\ Dr. Shreshtha Singh \\ Deptartment of Anaesthesia, \\ Datta Meghe Institute of Medical Science \\ (JNMC \& AVBRH) Sawangi, Wardha \\ Maharashtra, India. \\ E-mail: jayashree_sen@rediffmail.com
}

DOI: $10.14260 /$ jemds $/ 2020 / 170$

Financial or Other Competing Interests: None.

How to Cite This Article:

Sen J, Singh S, Sen B. The effect of intrathecal magnesium sulphate on bupivacaine-fentanyl subarachnoid block for infraumbilical surgeries. J. Evolution Med. Dent. Sci. 2020;9(10):780-785, DOI: 10.14260/jemds/2020/170

Submission 29-12-2019,

Peer Review 08-02-2020

Acceptance 14-02-2020,

Published 09-03-2020.

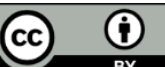




\section{BACKGROUND}

Since the introduction of spinal anaesthesia into clinical practice by Karl August Bier on August 16,(1) 1898, at the Royal Surgical Hospital of the University of Kiel, Germany, it remains one of the most popular techniques for both elective and emergency surgical procedures particularly caesarean sections, lower abdominal surgeries, orthopaedic and urological surgeries to name a few.(2) In an attempt $(3,4)$ to lengthen analgesia and decrease the incidence of side effects various classes of drugs such as benzodiazepines, ketamine, clonidine, opioids, epinephrine, neostigmine have been added as adjuvants to local anaesthetics. A phenylpiperidine derivative, fentanyl, is a synthetic $\mu$ opioid receptor agonist. It is preferred as an adjuvant in spinal anaesthesia because of its rapid onset, longer duration and intense effects on subarachnoid block. Opioids mimic the action of endogenous ligands (endorphins, enkephalins, dynorphins) by binding to opioid receptors causing activation of pain modulation (antinociceptive system). This leads to decrease in neurotransmission by presynaptic inhibition of neurotransmission (Acetylcholine, dopamine, norepinephrine) release. Moreover, when administered intrathecally, it does not have the tendency to migrate to the fourth ventricle in sufficient concentration. However, the use of opioids may be limited by significant side effects such as pruritus, urinary retention, haemodynamic instability, respiratory depression, occasionally(5) severe nausea and vomiting. Magnesium parenterally, which has been used on an empirical basis for analgesia in intra and postoperative period for many years, decreases the requirements of postoperative opioid. The analgesic effect of magnesium is due to its effect on NMDA receptors. Furthermore, it is coupled with ion channels such as $\mathrm{K}^{+}$and $\mathrm{Ca}^{++(6,7)}$ Magnesium causes a voltagedependent block on NMDA receptors. This NMDA channel antagonism causes insufficient penetration in blood brain barrier to achieve effective concentrations in cerebrospinal fluid.

A few clinical trials have examined the effect of adding intrathecal magnesium sulphate $\left(\mathrm{MgSO}_{4}\right)$ to ${ }^{(8,9)}$ Anaesthetic agents such as bupivacaine. The first randomized human study of intrathecal (IT) magnesium in 1906, as an antinociceptive non-competitive NMDA antagonist modulator, has shown(10) prolongation of the analgesic effect of opioids in spinal analgesia.(4) Histopathological analysis including safety profile, has also been evaluated. We hypothesize that the sideeffect of larger doses of intravenous magnesium that may be required to observe modulation in antinociception in humans can be avoided by intrathecal magnesium which can potentiate opioid spinal analgesia. Therefore, the present study was designed to examine whether the analgesic efficacy of intrathecal bupivacaine and fentanyl could be enhanced by addition of intrathecal magnesium sulphate in patients undergoing infra umbilical surgeries.

We wanted to evaluate the effect of intrathecal magnesium sulphate to bupivacaine-fentanyl subarachnoid block for infraumbilical surgeries by studying the efficacy, onset, duration of analgesia, haemodynamic variability during the block, duration of motor block and adverse effects if any of the drugs.

\section{METHODS}

This is a prospective, randomised, controlled, observational study. The study period was from September 2016 to August 2018, carried out in the department of Anaesthesia of a tertiary care hospital. Having obtained the Institutional Ethical Committee permission and informed consent from the patients, they were randomly allocated into two groups of 35 each using computer generated data.

The sample size was calculated based on results from a similar study ${ }^{(10)}$ and using the following formula-

$$
n_{1}=\frac{\left(\sigma_{1}^{2}+{\sigma_{2}}^{2} / K\right)\left(\mathrm{Z}_{1-\alpha / 2}+Z_{1-\beta}\right)^{2}}{\Delta^{2}}
$$

The notation for the formulae are:

$n_{1}=$ sample size of Group 1

$n_{2}=$ sample size of Group 2

$\sigma_{1}=$ standard deviation of Group 1

$\sigma_{2}=$ standard deviation of Group 2

$\Delta=$ difference in group means

$\kappa=$ ratio $=\mathrm{n}_{2} / \mathrm{n}_{1}$

$Z_{l-a / 2}=$ two-sided $Z$ value (eg. $Z=1.96$ for $95 \%$ confidence interval).

$Z_{l-\beta}=$ power

SD of time to onset of motor block of control group $=1.0$

SD of time to onset of motor block of magnesium group =

$0.71^{(9)}$

$\Delta=$ Difference in mean value $=5.7-5.1=0.6$ $\mathrm{K}=1$

$$
N=\frac{(1 * 1+0.71 * 0.71)(1.96+0.84)^{2}}{0.6 * 0.6}
$$

$=32.66$

$=32$

Considering a dropout rate of $10 \%$ i.e. 3.2, total sample size should be $=32+3.2=35.2=35$ patients needed in each study.

The patients in Group-S (control), intrathecal administration of $2.5 \mathrm{~mL}(12.5 \mathrm{mg})$ of hyperbaric bupivacaine, $0.5 \mathrm{~mL}(25 \mathrm{mcg})$ of fentanyl, $1 \mathrm{~mL}$ of normal saline - total volume $4 \mathrm{ml}$ Group-M (study), intrathecal administration of $2.5 \mathrm{~mL}(12.5 \mathrm{mg})$ of hyperbaric bupivacaine, $0.5 \mathrm{~mL}$ ( $25 \mathrm{mcg}$ ) of fentanyl, $1 \mathrm{ml}(50 \mathrm{mg}$ ) inj. of magnesium sulphate - total volume $4 \mathrm{ml}$.

\section{Inclusion Criteria}

Patients posted for infra umbilical surgeries who were

- $\quad$ willing to give informed consent

- belonging to ASA physical status I and II, of either gender

- $\quad$ age group 18 to 70 years

- $\quad$ weight $>40 \mathrm{~kg}$

- $\quad$ height $>145 \mathrm{cms}$

\section{Exclusion Criteria}

- not willing to give consent

- $\quad$ past history of reaction to the study drugs

- having hepatic, renal or cardiovascular dysfunction

- with h/o allergy to local anaesthetics 
- $\quad$ with acid peptic disorder

- on anti-emetic medications

- with bleeding coagulopathy

- obese

- pregnant

- $\quad$ any contraindication to central neuraxial blockade

\section{Pre-Anaesthetic Assessment:}

One day prior to the proposed surgery, all the patients were visited, preanaesthetic check-up was done, detailed examination including history, systemic examination of cardiovascular, respiratory, central nervous system and examination of spine for infection or deformity was carried out. The procedure of spinal anaesthesia was explained to the patients. Routine investigations like complete haemogram, blood grouping, blood urea, serum creatinine, blood sugar, routine urine examination, electrocardiogram, chest X-ray were done. The patients were educated about the use of verbal analogue scale (VAS).(11)

Since the perception of pain is highly subjective, this variable was standardized by using data from VAS. First advocated by Revill and Robinson in 1976, VAS consists of a $10 \mathrm{~cm}$ line where at one end a label as "no pain" and at the other end "unbearable pain" was anchored. The patient simply marks the line to indicate the pain intensity and the provider then measures the length of the line marked on a point scale.

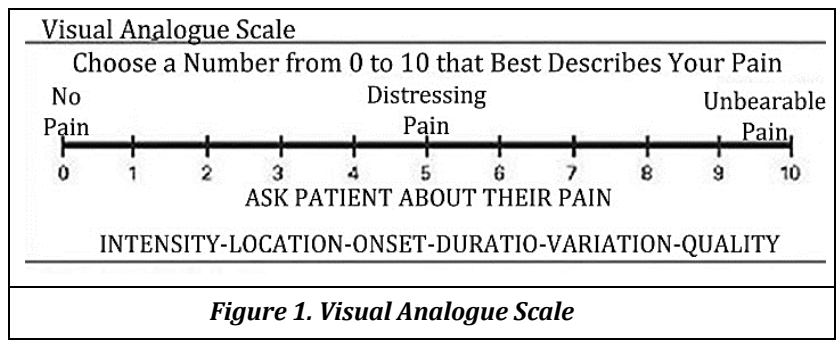

\section{NBM Period}

The patients included in the study were kept nil orally for 8 hrs. Standard preoperative procedure were followed and 18G IV cannula was secured. In the operation theatre, routine monitors (pulse oximeter, electrocardiogram, noninvasive blood pressure, $\mathrm{EtCO}_{2}$ ) were attached. The patients were preloaded with Ringer Lactate $10 \mathrm{ml} / \mathrm{kg}$ to prevent intraoperative hypotension. Subarachnoid block was administered to patients with 23G Quincke Spinal needle in lateral position the L3-L4 interspace. One group received magnesium sulphate with bupivacaine and fentanyl and other control group received normal saline with bupivacaine and fentanyl. The patients were then immediately turned to supine position. Oxygenation was given via a Hudson mask at the rate of $3 \mathrm{~L} / \mathrm{min}$.

Sensory block was assessed by a pinprick test. The time from the injection of intrathecal drugs to the absence of pain on prick at the T8 dermatome was recorded which had been defined as the onset of sensory blockade. The duration of analgesia was recorded as the time from intrathecal injection until the patient's request for additional analgesic. Intramuscular diclofenac $(75 \mathrm{mg}$ ) as rescue analgesic on demand were then administered in the post-operative period.
The intensity of pain was assessed via Visual Analogue Scale (VAS) from the time of induction i.e. the baseline T1 (0 min), then at T2 (30 mins), T3 (1 hr), T4 (4 hrs.) T5 (8 hrs), till T6 (12 hrs) in the post-operative period. Motor blockade was assessed according to the modified Bromage Scale. The onset of motor blockade was defined as the time from the injection of intrathecal drugs till the Grade 3 was at-(12) tainted and recovery from the motor block was taken as the time from intrathecal injection until the value regressed to Grade 0 of modified Bromage Scale. Modified Bromage Scale.

\begin{tabular}{|c|c|c|}
\hline Grade & Criteria & Degree of block \\
\hline 0 & Free movement of legs and feet & Nil (0\%) \\
\hline I & Just able to flex knee with free movement of feet & Partial (33\%) \\
\hline II & Unable to flex knee with free movement of feet & Partial (66\%) \\
\hline III & Unable to move legs or feet & $\begin{array}{c}\text { Complete paralysis } \\
(100 \%)\end{array}$ \\
\hline \multicolumn{2}{|c|}{ Modified Bromage Scale } \\
\hline
\end{tabular}

Blood pressure (systolic and diastolic), heart rate, respiratory rate were recorded from the time of intrathecal injection i.e at $0 \mathrm{~min}$ and at $5,10,15,20,25,30 \mathrm{~min}$ after the injection, and subsequently every 15 min till 120 mins. Hypotension [defined as less than $20 \%$ of baseline of diastolic or systolic blood pressure] was treated with IV fluid $250 \mathrm{ml}$ bolus initially, repeated twice then IV mephentermine.(13) 6 $\mathrm{mg}$, if required Bradycardia [defined as heart rate of less than $50 \mathrm{bpm}$ ] was treated with $0.6 \mathrm{mg}$ atropine sulphate IV.

\section{Statistical Analysis}

Statistical analysis was done by using descriptive and inferential statistics using chi-square test and student's unpaired test and software used in the analysis were SPSS 22.0 version and GraphPad Prism 6.0 version. $\mathrm{p}<0.05$ is considered as level of significance (S). NS signifies nonsignificant.

\section{RESULTS}

\begin{tabular}{|c|c|c|c|c|}
\hline Parameter & Group S $(n=35)$ & Group M (n=35) & T value & p value \\
\hline Age (years) & $42.9 \pm 12.4$ & $44.7 \pm 12.0$ & 0.5392 & 0.6171 \\
\hline Gender (Male) & $22(62.86 \%)$ & $22(62.86 \%)$ & 0.00 & $1.00, \mathrm{NS}$ \\
\hline Gender (Female) & $13(37.14 \%)$ & $13(37.14 \%)$ & 0.00 & $1.00, \mathrm{NS}$ \\
\hline Weight (kg) & $59.8 \pm 4.4$ & $59.2 \pm 7.5$ & 0.70 & $0.38, \mathrm{NS}$ \\
\hline Height (cm) & $157.7 \pm 2.6$ & $158.1 \pm 4.0$ & 0.57 & $0.55, \mathrm{NS}$ \\
\hline ASA grade I & $18(51.43 \%)$ & $18(51.43 \%)$ & 0.00 & $1.00, \mathrm{NS}$ \\
\hline ASA grade II & $17(48.57 \%)$ & $17(48.57 \%)$ & 0.00 & $1.00, \mathrm{NS}$ \\
\hline \multicolumn{5}{|c|}{ Table 1. Demographic Profile } \\
\hline & Group S $(n=35)$ & Group M (n= 35) & t value & p value \\
\hline $\begin{array}{c}\text { Onset of sensory } \\
\text { block (min) }\end{array}$ & $5.3 \pm 1.0$ & $7.8 \pm 1.2$ & 9.4697 & $<0.00001, \mathrm{~S}$ \\
\hline
\end{tabular}

\begin{tabular}{|l|c|c|c|c|}
\hline & $\begin{array}{c}\text { Group S } \\
\text { (n= 35) }\end{array}$ & $\begin{array}{c}\text { Group M } \\
\text { (n= 35) }\end{array}$ & t value & p value \\
\hline $\begin{array}{l}\text { Onset of motor block(min) } \\
\text { modified Bromage score 3 }\end{array}$ & $10.4 \pm 2.1$ & $13.2 \pm 1.5$ & 6.4191 & $<0.00001, \mathrm{~S}$ \\
\hline
\end{tabular}

Table 3: Onset of Motor Block (Min) in Group S and Group M

\begin{tabular}{|c|c|c|c|c|}
\hline & $\begin{array}{c}\text { Group S } \\
\text { (n= 35) }\end{array}$ & $\begin{array}{c}\text { Group M } \\
\text { (n= 35) }\end{array}$ & t value & p value \\
\hline Duration of analgesia (min) & $261.3 \pm 12.2$ & $290.3 \pm 9.5$ & 11.0958 & $<0.00001, \mathrm{~S}$ \\
\hline $\begin{array}{c}\text { Recovery of motor block(min) } \\
\text { modified Bromage score 0 }\end{array}$ & $236.5 \pm 5.5$ & $242.5 \pm 9.4$ & 3.2593 & $0.002, \mathrm{~S}$ \\
\hline
\end{tabular}

Table 4. Duration of Analgesia (Min) and Recovery of Motor Blockade (Min) in Group $S$ and Group M 

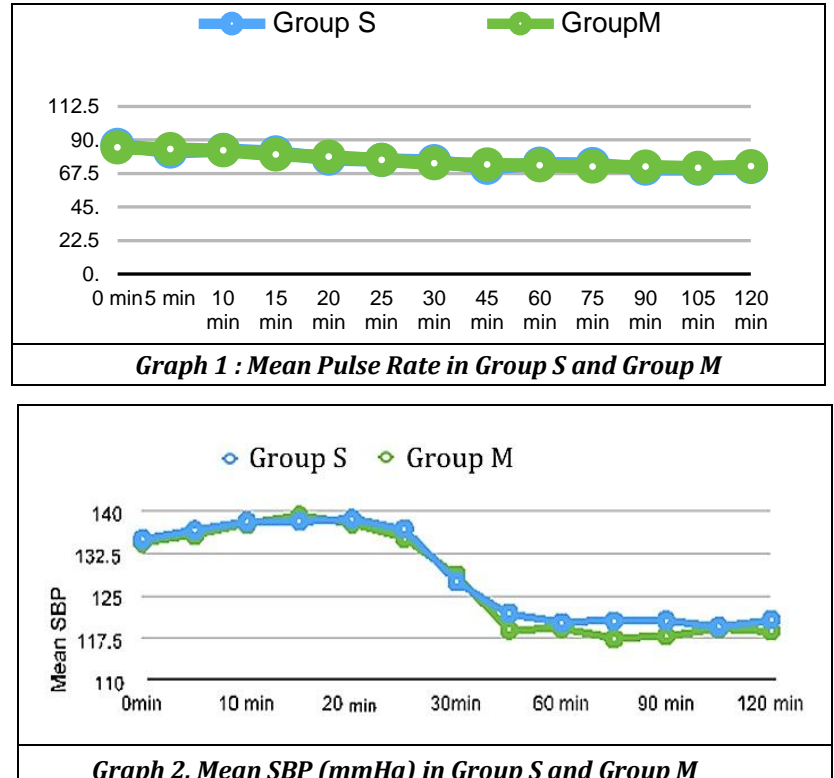

Graph 2. Mean SBP (mmHg) in Group S and Group M
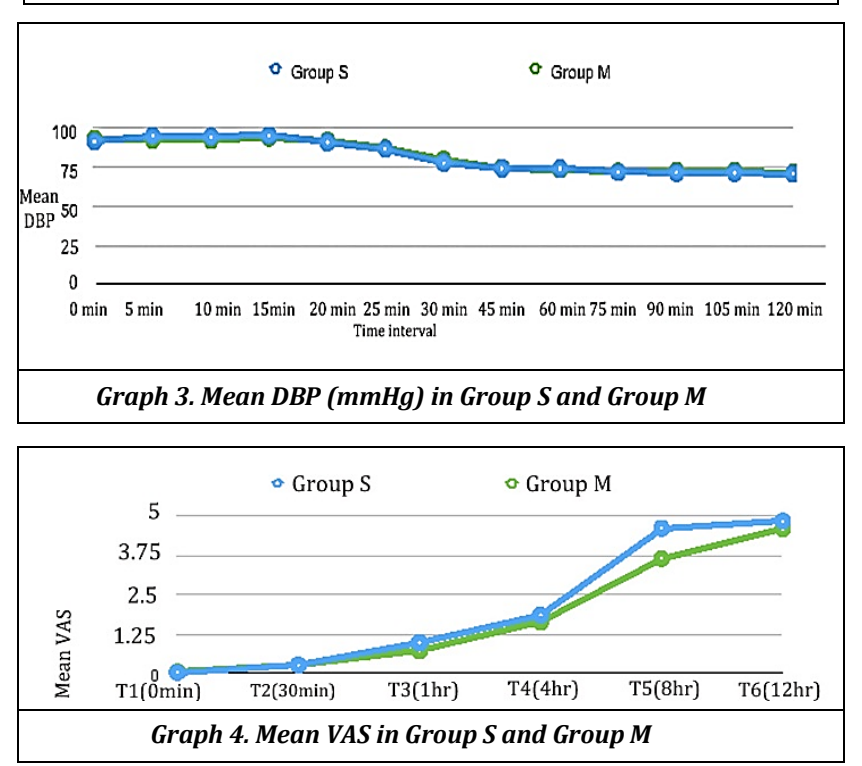

\section{DISCUSSION}

An unpleasant sensory and emotional experience associated with actual or potential tissue damage can be described as pain. Alleviation of pain is a boon of anaesthesia. Various methods of post-operative pain relief are through Systemic approaches with opioids or non-opioids like NSAIDS etc. Regional approaches with peripheral nerve blocks or neuraxial blockade with either epidural, or subarachnoid block, etc. Spinal anaesthesia or subarachnoid block, is a temporary interruption of nerve transmission within the subarachnoid space, used for almost 100 years widely, safely, successfully which follows an injection of a local anaesthetic solution given into cerebrospinal fluid and has many potential advantages over general anaesthesia, especially for operations involving the lower abdomen, the perineum and the lower extremities. The commonly used drugs for spinal subarachnoid block are local anaesthetics lignocaine and bupivacaine. One disadvantage with spinal anaesthesia using local anaesthetics alone is that analgesia ends with the regression of the block, which means that there is an early postoperative need for analgesia. Post-operative pain, apart from causing discomfort has other deleterious effects involving mainly the cardio-respiratory system. Intrathecal adjuvants while added to the local anaesthetics, increase the duration of analgesia, thus prolongs post-operative pain relief and reduced requirements of post-operative analgesic, facilitating early ambulation enabling the patients to return to their routine activity more quickly ${ }^{(14)}$ cutting short the hospital stay.

With the discovery of the N-methyl-d-aspartate (NMDA) receptors and its links to central sensitization and nociceptive pain transmission, NMDA receptor antagonist plays an important role in the prevention of central sensitization of pain. Glutamate and aspartate neurotransmitters are released in response to noxious stimuli and bind to the NMDA receptors and various other excitatory amino acid receptors. NMDA receptors activation leads to calcium and sodium influx into the cell, efflux of potassium, antagonisation of $\mathrm{N}$ methyl D-aspartate (NMDA) receptors and initiation of central sensitization(15,16). There are no selective NMDA receptor antagonists available for pain management; so the drugs with non-competitive NMDA receptor antagonists, such as magnesium sulphate, ketamine have shown promise as analgesics.(17)

The rationale of intrathecal (IT) Magnesium administration as an adjuvant for the present study was based on certain published supportive datas.(18) Haubold and Meltzer gave 1000-2000 mg IT in orthopaedic, general surgical, and gynaecological procedures which produced profound motor and sensory block for 3-27 h with complete recovery. Intrathecal $\mathrm{MgSO}_{4}$ as an adjuvant to spinal bupivacaine may alter bupivacaine pharmacokinetics and cause a more rapid elimination of bupivacaine.(19) This effect was supported recently by Hung et al ${ }^{(20)}$ who found an inverse relationship between IT magnesium sulphate and amide local anaesthetics. Buvendran et $\mathrm{al}^{(8)}$ postulated that the side effects caused by larger doses of IV Magnesium which may be required to observe antinociceptive modulation in humans can be avoided by intrathecal magnesium administration which can potentiate opioid spinal analgesia. In a systematic review and meta-analysis, A. P. Morrison et al(21) in 2013 has demonstrated no effect on duration of spinal anaesthesia with the addition of magnesium to LA alone. However, in the presence of intrathecal opioids, they found a beneficial effect, which suggested that magnesium potentiates the effect of opioids. The use of intrathecal opioids is associated with the risk of respiratory depression(22). Varassi et al(23) reported that the subarachnoid administration of $25 \mu \mathrm{g}$ of fentanyl during spinal anaesthesia did not cause early respiratory depression in elderly non pre-medicated men patients. Table 1 , shows the demographic profile statistically non-significant (NS).As per Graph no. 1,2,3 both the groups were comparable throughout the study period with regard to mean of heart rate, systolic and diastolic blood pressure. On addition of magnesium to the spinal block, our study found insignificant haemodynamic variability. This may be due to the absence of systemic vasodilator effects of subarachnoid magnesium,(24,25) though IV magnesium when used to treat eclampsia (25) is known to cause fall in blood pressure. Our results supported the studies conducted by Nath MP et al,(13) Jaiswal R et at (24) and Kaur Grewal et al(25) where stable haemodynamics with addition of magnesium sulphate were observed. 
As per Table no.2, onset of sensory block ( $\mathrm{min}$ ) in group S was $5.3 \pm 1.0$ and in group $M$ was $7.8 \pm 1.2$ which was found to be statistically significant with t-value 9.4697 and p-value of $<0.00001$, the delay in onset of sensory block in group $\mathrm{M}$ could be due to different $\mathrm{pH}$ and baricity of magnesium sulphate solution.This might explain our findings(8). Buvanendran et $\mathrm{al}^{(8)}$ measured the baricity of magnesium sulphate mixed with fentanyl using refractometry and found it to be slightly hypobaric with respect to CSF. Activation of cytochrome P450 (CYP) by magnesium, increases the metabolism of bupivacaine which may be the reason for the delayed onset. $(21,19)$ Our results are in accordance with Nath MP et al,(13) Jaiswal R et at (26) and Kaur Grewal et al.(27) They also found similar results in the onset of sensory block. In our study, as per Table no. 3 the motor block onset in the group of magnesium sulphate is $(13.2 \pm 1.5)$ min when compared to control group $(10.4 \pm 2.1)$ min which is statistically significant (p-value $<0.00001$ ) so, there is a delay in the onset of motor block when intrathecal magnesium was used as an adjuvant. This result was found similar to the study performed by Malleeswaran et al(9) in 2010 and also Nath et al.(13) The delay in onset of motor blockade could be due to different $\mathrm{pH}$ and baricity of magnesium sulphate solution.

As per Table no. 4 the mean duration of analgesia was $261.3 \pm 12.2$ mins in group S but in group M it was $290.3 \pm 9.5$ mins. The probability value as detected by two sample students $t$ test is 11.0958. This implies that addition of intrathecal magnesium sulphate to bupivacaine and fentanyl prolonged the period of analgesia. The increase in duration of analgesia between the two group was statistically significant in our study with the p-value $<0.00001$. This correlates with the studies done by Rajesh Vasur et al(28) in 2016 and Nath MP et al,(13) M. Ozalevli et al(29) and also Buvendran et al(8) in 2002. They all concluded that addition of intrathecal magnesium sulphate to bupivacaine and fentanyl prolonged the period of analgesia.

The recovery from the motor block [table no. 4] in our study was assessed as per the modified Bromage score which was considered when the score reached to a value 0 . During that period of time, in our study group, it was $242.5 \pm 9.4 \mathrm{~min}$ and in control group it was $236.5 \pm 5.5 \mathrm{~min}$ and the difference was found to be statistically significant ( $p$ - value of 0.002).This finding was in accordance to the study done by Bala Subramani Murugesan et al(30) in 2016, Malleswarum et al in 2010(9) and Limbu et al.(31) But in the study by Limbu et al(31) duration of motor block in patients of magnesium group was not statistically significant. Unlugenc et al(32) in 2009 observed in their study that median duration of motor blockade in magnesium sulphate group when used with bupivacaine(group m) but without fentanyl, was significantly shorter in comparison to control group (group C). This contradicts our study result on recovery from motor blockade where we have found that magnesium delays motor recovery.

The intensity of pain was assessed by Visual Analogue Scale (VAS).(11) As per Graph no. 4 in our study, only at $8^{\text {th }} \mathrm{hr}$ in Group S mean of VAS was $4.62 \pm 0.68$ and in Group M it was $3.65 \pm 0.90$ this result was found to be statistically significant, with $\mathrm{p}$-value of $<0.00001$ which signifies that magnesium as an adjuvant in spinal sub arachnoid block had decreased the VAS from the group where magnesium was not added. The episode of hypotension in the present study, in table no. 5 shows that $6(17.14 \%)$ patients in control group and 8
(22.86\%) patients in study group had to be treated with IV fluid (250 ml boluses repeated twice) initially and later IV 6 mg of mephentermine. The episodes of hypotension was statistically insignificant in both the groups. Bradycardia was found in 6 patients (17.14\%) in control group and 5(14.29\%) in study group, the comparison was statistically insignificant and was treated with injection atropine $0.6 \mathrm{mg}$ IV. Shivering was complained by $5(14.29 \%)$ patients in control group and $4(11.43 \%)$ patients in study group which was treated using warm IV.(33) fluid and covering the patients with warm clothes. The result was also found to be statistically insignificant. None of the patients in any of the two groups had any episode of respiratory depression, pruritis, nausea or vomiting. From the above findings we can claim that in the present study, the incidence of side effects were similar in both the groups. This result correlates with the,(13).(9) studies done by Nath et al in 2012, Malleeswaran et al in 2012.

\section{CONCLUSIONS}

Addition of $50 \mathrm{mg}$ intrathecal magnesium sulphate to $12.5 \mathrm{mg}$ bupivacaine and $25 \mathrm{mcg}$ fentanyl, in subarachnoid block for infraumbilical surgeries, significantly prolongs the onset, duration of analgesia, as well as the onset and recovery from motor block, decreases the mean of VAS in the group where magnesium was not added. There are no significant haemodynamic variations and adverse effects.

\section{REFERENCES}

[1] Parameshwara G. Spinal, epidural to combined spinal epidural analgesia, the history of central neuraxial block. Indian J Anaesth 2001;45(6):406-12.

[2] Dureja GP, Jayalaxmi TS. Colloid preloading before spinal and epidural anaesthesia. Hospital Today 2000;5(11):601-3.

[3] Racle JP, Benkhadra A, Poy JY, et al. Prolongation of isobaric bupivacaine spinal anaesthesia with epinephrine and clonidine for hip surgery in the elderly. Anaesth Analg 1987;66(5):442-6.

[4] Lysakowski C, Dumont L, Czarnetzki C, et al. Magnesium as an adjuvant to postoperative analgesia: a systematic review of randomized trials. Anaesth Analg 2007;104(6):1532-9.

[5] Eti Z, Umuroglu T, Takil A, et al. The comparison of the effects and side effects of local ansethetic and opioid combinations in epidural patient controlled analgesia. Agri 2005;17(2):34-9.

[6] Nowak L, Bregestovski P, Ascher P, et al. Magnesium gates glutamate-activated channels in mouse central neurones. Nature 1984;307(5950):462-5.

[7] Ascher P, Nowak L. Electrophysiological studies of NMDA receptors. Trends Neurosci 1987;10(7):284-8.

[8] Buvanendran A, McCarthy RJ, Kroin JS, et al. Intrathecal magnesium prolongs fentanyl analgesia: a prospective, randomized, controlled trial. Anaesth Analg 2002;95(3):661-6. 
[9] Malleeswaran S, Panda N, Mathew P, et al. A randomised study of magnesium sulphate as an adjuvant to intrathecal bupivacaine in patients with mild preeclampsia undergoing caesarean section. Int J Obstet Anaesth 2010;19(2):161-6.

[10] Chanimov M, Cohen ML, Grinspun Y, et al. Neurotoxicity after spinal anaesthesia induced by serial intrathecal injections of magnesium sulphate. An experimental study in a rat model. Anaesthesia 1997;52(3):223-8.

[11] Loeser JD, Butler SH, Chapman CR, et al. Neorophysiology and taxonimy of pain-measurement of pain. In: Loeser JD, ed. Bonicas management of pain. $3^{\text {rd }}$ edn. Philadelphia: Lippincott Williams \& Wilkins 2001:153-9.

[12] McNamee DA, McClelland AM, Scott S, et al. Spinal anaesthesia: comparison of plain ropivacaine $5 \mathrm{mg} \mathrm{ml}(-$ 1) with bupivacaine $5 \mathrm{mg} \mathrm{ml}(-1)$ for major orthopaedic surgery. Br J Anaesth 2002;89(5):702-6.

[13] Nath MP, Garg R, Talukdar T, et al. To evaluate the efficacy of intrathecal magnesium sulphate for hysterectomy under subarachnoid block with bupivacaine and fentanyl: a prospective randomized double blind clinical trial. Saudi J Anaesth 2012;6(3):2548.

[14] Shukla D, Agarwal A, Pandey HD, et al. Comparative study of dexmedetomidine with intrathecal magnesium sulphate used as adjuvant to bupivacaine. J Anaesthesiol Clin Pharmacol 2011;27(4):495-9.

[15] Woolf CJ, Thompson SW. The induction and maintenance of central sensitization is dependent on N-methyl-Daspartic acid receptor activation: implications for the treatment of post-injury pain and hypersensitivity states. Pain 1991;44(3):293-9.

[16] Woolf CJ, Chong MS. Preemptive analgesia--treating postoperative pain by preventing the establishment of central sensitization. Anaesth Analg 1993;77(2):362-79.

[17] Liu HT, Hollman MW, Liu WH, et al. Modulation of NMDA receptor function by ketamine and magnesium: Part I. Anaesth Analg 2001;92(5):1173-81.

[18] Haubold HA, Meltzer SJ. Spinal anaesthesia by magnesium sulfate. J Am Med Assoc 1906;46:647-50.

[19] Okutomi T, Saito M, Matsumoto $Y$, et al. Altered bupivacaine pharmacokinetics by $\mathrm{MgSO} 4$ in rats. Can J Anaesth 2004;51(1):93-4.

[20] Hung YC, Chen CY, Lirk P, et al. Magnesium sulfate diminishes the effects of amide local anaesthetics in rat sciatic-nerve block. Reg Anaesth Pain Med 2007;32(4):288-95.

[21] Morrison AP, Hunter JM, Halpern SH, et al. Effect of intrathecal magnesium in the presence or absence of local anaesthetic with and without lipophilic opioids: a systematic review and meta-analysis. $\mathrm{Br} \mathrm{J}$ Anaesth 2013;110(5):702-12.

[22] Etches R, Sandler A, Daley M. Respiratory depression and spinal opioids. Can J Anaesth 1989;36(2):165-85.

[23] Varrassi G, Celleno D, Capogna G, et al. Ventilatory effect of subarachnoid fentanyl in the elderly. Anaesthesia 1992;47(7):558-62.

[24] Duley L, Watkins K. Magnesium sulphate for treatment of preeclampsia: a trial to evaluate the effects on women and their babies. Contemp Rev Obstet Gynaecol 1998;10:267-74.

[25] Witlin AG, Sibai BM. Magnesium sulfate therapy in preeclampsia and eclampsia. Obstet Gynecol 1998;92(5):883-9.

[26] Jaiswal R, Bansal T, Kothari S, et al. The effect of adding magnesium sulphate to bupivacaine for spinal anaesthesia: a randomised, double- blind trial in patients undergoing lower limb orthopaedic surgery. Int J Pharm Pharm Sci 2013;5(4):179-82.

[27] Grewal TK, Sharma A, Bhupal JPS, et al. To evaluate the efficacy of intrathecal bupivacaine versus bupivacaine, fentanyl and magnesium sulphate in spinal anaesthesia for transabdominal hysterectomy. International Journal of Current Medical and Pharmaceutical 2016;2(8):561-5.

[28] Vasure R, Ashahiya ID, Narang N, et al. Comparison of effect of adding intrathecal magnesium sulfate to bupivacaine alone and bupivacaine-fentanyl combination during lower limb orthopedic surgery. Int J Sci Stud 2016;3(10):141-6.

[29] Ozalevli M, Cetin TO, Guler T. The effect of adding intrathecal magnesium sulphate to bupivacaine -fentanyl spinal anaesthesia. Acta Anaesthesiol Scand 2005;49(10):1514-9.

[30] Murugesan BS, Ramakrishnan CD. The effect of adding intrathecal magnesium sulphate to bupivacaine- fentanyl spinal anaesthesia. J Evolution Med Dent Sci 2016;5(98):7185-91.

[31] Limbu PM, Sindhu K, Singh SN, et al. Intrathecal magnesium sulfate as analgesic and anaesthetic adjunct to bupivacaine in patients undergoing lower extremity orthopaedic surgery. Journal of Society of Anaesthesiologists of Nepal 2017;4(2):74-80.

[32] Unlugenc H, Ozalevli M, Gunduz M, et al. Comparison of intrathecal magnesium, fentanyl, or placebo combined with bupivacaine $0.5 \%$ for parturients undergoing elective cesarean delivery. Acta Anaesthesiol Scand 2009;53(3):346-53.

[33] Luggya TS, Kabuye RN, Mijumbi C, et al. Prevalence, associated factors and treatment of post spinal shivering in a Sub-Saharan tertiary hospital: a prospective observational study. BMC Anaesthesiol 2016;16(1):100. 